\title{
Multimorbidity in Elderly Persons According to the Year of Diagnosis of Human Immunodeficiency Virus Infection: A Cross-sectional Dat'AIDS Cohort Study
}

\begin{abstract}
Marie Demontès, ${ }^{1}$ Sabrina Eymard Duvernay, ${ }^{2}$ Clotilde Allavena, ${ }^{3}$ Thomas Jovelin, ${ }^{3}$ Jacques Reynes, ${ }^{4}$ Maxime Hentzien, ${ }^{5}$ Isabelle Ravaux, ${ }^{6}$ Pierre Delobel, ${ }^{7}$ Sylvie Bregigeon, ${ }^{8}$ David Rey, ${ }^{9}$ Tristan Ferry, ${ }^{10}$ Amandine Gagneux-Brunon, ${ }^{11}$ Olivier Robineau, ${ }^{12}$ Pascal Pugliese, ${ }^{13}$ Claudine Duvivier, ${ }^{14}$ André Cabié, ${ }^{15}$ Catherine Chirouze, ${ }^{16}$ Christine Jacomet, ${ }^{17}$ Isabelle Lamaury, ${ }^{18}$ Dominique Merrien, ${ }^{19}$ Bruno Hoen, ${ }^{16}$ Laurent Hocqueloux, ${ }^{20}$ Antoine Cheret, ${ }^{21,22}$ Christine Katlama, ${ }^{23}$ Cédric Arvieux, ${ }^{24}$ Pierre Krolak-Salmon, ${ }^{1}$ and Alain Makinson ${ }^{4}$; for the Dat'AIDS Study Group ${ }^{a}$

${ }^{1}$ Memory Clinical and Research Center of Lyon, Lyon Institute for Elderly, Hospices civils de Lyon, Université Lyon 1, Inserm 1048, Lyon, France, ${ }^{2}$ University of Montpellier, Unité TransVIHMI, France Institute of Research for Development Unité Mixte Internationale (UMI) 233, Inserm U1175, Montpellier, France, ${ }^{3}$ Infectious Diseases Department, University of Nantes, Centre hospitalier universitaire Hôtel Dieu, Nantes, France, ${ }^{4}$ Infectious and Tropical Diseases Department, Montpellier University Hospital, and UMI 233, Inserm U1175, Montpellier, France, ${ }^{5}$ Reims Teaching Hospitals, Robert Debré Hospital, Department of Internal Medicine, Infectious Diseases, and Clinical Immunology, Reims, France, ${ }^{6}$ Aix Marseille Université, Centre Nationale de la Recherche Scientifique (CNRS), Institut de Recherche pour le Développement (IRD), Inserm, Assistance Publique-Hôpitaux de Marseille (AP-HM), Unité de Recherche sur les Maladies Infectieuses, Institut Hospitalo-Universitaire (IHU) Méditerranée-Infection, Marseille, France, ${ }^{7}$ Infectious and Tropical Diseases Department Inserm, Unité Mixte de Recherche (UMR) 1043, Toulouse, France, ${ }^{8}$ Aix Marseille Universiteé, AP-HM Sainte-Marguerite, Marseille, France, ${ }^{9}$ University Hospitals of Strasbourg, Nouvel Hôpital Civil, Human Immunodeficiency Virus Care Center, Strasbourg, France, ${ }^{10}$ Infectious Diseases Department, Hospices Civils de Lyon, Claude Bernard Lyon 1 University, Lyon, France, ${ }^{11}$ Department of Infectious and Tropical Diseases, Centre hospitalier universitaire Saint-Etienne, Groupe Immunité des Muqueuses et Agents Pathogènes, Jean Monnet University, University of Lyon, Saint-Etienne, France, ${ }^{12}$ Infectious Diseases Department, Gustave Drion Hospital, Tourcoing, France, ${ }^{13}$ Infectious Diseases Department, University of Nice, Centre hospitalier universitaire L'Archet, Nice, France, ${ }^{14}$ Assistance Publique-Hôpitaux de Paris (AP-HP), Hôpital Necker-Enfants malades, Infectious and Tropical Diseases Department, Institut Pasteur, Centre Médical de I'Institut Pasteur, Infectious Diseases Centre Necker-Pasteur, IHU Imagine, Institut Cochin, CNRS 8104, Inserm U1016, Paris, France, ${ }^{15}$ Clinical Investigation Centre, Antilles Guyane, Inserm 1424 and Infectious and Tropical Diseases Department, Centre Hospitalier Universitaire de la Martinique and University of the Antilles, Equipe d'Acceuil 4537, Fort-de-France, France, ${ }^{16}$ Infectious and Tropical Diseases Department, Centre Hospitalier Regional Universitaire Besançon, UMR CNRS 6249 Bourgogne Franche Comté University, Besançon, France, ${ }^{17}$ Infectious Diseases Department, Centre hospitalier universitaire Clermont-Ferrand, Clermont-Ferrand, France, ${ }^{18}$ Department of Infectious and Tropical Diseases, Dermatology, Internal Medicine, University Hospital Guadeloupe, Pointe-à-Pitre, France, ${ }^{19}$ Internal Medicine Department, Centre Hospitalier Vendée (CHD) Vendée, La Roche-sur-Yon, France, ${ }^{20}$ Department of Infectious and Tropical Diseases, Centre hospitalier universitaire d'Orléans-La Source, Orléans, France, ${ }^{21}$ Internal Medicine Department, Centre hospitalier universitaire Bicètre, Bicètre, France, ${ }^{22}$ University of Paris Descartes, Sorbonne Paris Cité, Paris, France, ${ }^{23}$ Sorbonne Université, Inserm, Pierre Louis Institute of Epidemiology and Public Health, Unité Mixte de Recherche en Santé 1136, AP-HP, Hôpitaux Universitaires Pitié Salpêtrière-Charles Foix, Department of Infectious and Tropical Diseases, Paris, France, and ${ }^{24}$ Centre hospitalier universitaire Rennes, Infectious Diseases and Intensive Care Unit, Rennes, France
\end{abstract}

Background. We assessed prevalence of multimorbidity (MM) according to year of human immunodeficiency virus (HIV) diagnosis in elderly people living with HIV (PLWH).

Methods. This was a cross-sectional study of MM in PLWH aged $\geq 70$ years from the Dat'AIDS French multicenter cohort. MM was defined as at least 3 coexistent morbidities of high blood pressure, diabetes mellitus, osteoporosis, non-AIDS cancer, chronic renal failure, cardiovascular and cerebrovascular disease, obesity, undernutrition, or hypercholesterolemia. Logistic regression models evaluated the association between MM and calendar periods of HIV diagnosis (1983-1996, 1997-2006, and 2007-2018). The secondary analysis evaluated MM as a continuous outcome, and a sensitivity analysis excluded PLWH with nadir CD4 count $<200$ cells $/ \mu \mathrm{L}$.

Results. Between January 2017 and September 2018, 2476 PLWH were included. Median age was 73 years, 75\% were men, median CD4 count was 578 cells $/ \mu \mathrm{L}$, and $94 \%$ had controlled viremia. MM prevalence was $71 \%$. HBP and hypercholesterolemia were the most prevalent comorbidities. After adjustment for age, gender, smoking status, hepatitis $\mathrm{C}$ and hepatitis $\mathrm{B}$ virus coinfection, group of exposure, nadir CD4 count, $\mathrm{CD} 4 \mathrm{CD} 8$ ratio, and last $\mathrm{CD} 4$ level, calendar period of diagnosis was not associated with MM $(P=.169)$. MM was associated with older age, $\mathrm{CD} 4 / \mathrm{CD} 8$ ratio $<0.8$, and nadir $\mathrm{CD} 4$ count $<200$ cells $/ \mu \mathrm{L}$. Similar results were found with secondary and sensitivity analyses.

Conclusions. MM prevalence was high and increased with age, low CD4/CD8 ratio, and nadir CD4 count $<200$ cells $/ \mu \mathrm{L}$ but was not associated with calendar periods of HIV diagnosis. Known duration of HIV diagnosis does not seem to be a criterion for selecting elderly PLWH at risk of MM.

Keywords. elderly; HIV; multimorbidity; comorbidities; aging.

Received 2 August 2019; editorial decision 27 November 2019; accepted 7 December 2019; published online December 9, 2019.

aMembers of the Dat'AIDS Study Group are listed in the Appendix.

Correspondence: Marie Demontes, Hospices Civils de Lyon, Hospital Saint Joseph Saint Luc, 20 Quai Claude Bernard, 69007 Lyon, France (marie.demontes@hotmail.fr).
Most countries face an increase in the proportion of elderly persons in their general population. Aging is combined with an increased frequency of age-related diseases, their accumulation leading to multimorbidity (MM), defined as the concomitant occurrence of multiple chronic conditions within the same individual [1]. MM has a significant burden on individuals and healthcare systems, including increasing mortality, reducing functional status, and increasing strain on health systems $[2$, 
3]. Estimates of $M M$ in geriatric populations (aged $\geq 65$ years) have ranged from $55 \%$ to $98 \%$, varying according to populations studied and definitions of MM used [4].

Since the widespread use of highly effective combined antiretroviral therapy (cART) in resource-rich settings, human immunodeficiency virus (HIV) has become a chronic disease, and life expectancy in people living with HIV (PLWH) has increased [5, 6]. The number of people aging with HIV is consequently growing [7], along with incidence of age-related noncommunicable diseases and related deaths [8]. The incidence of MM will increase in PLWH through the natural process of aging, but some HIV-related factors may modulate MM incidence. HIV per se, and its correlate of chronic immunodeficiency and immune activation, is implicated in accelerated aging [9]. First generations of cART have also been associated with the incidence of some comorbidities, particularly with metabolic and cardiovascular syndromes [10-12]. There is also a high prevalence of behavioral hazards in PLWH, such as smoking [13], cannabis consumption [14], or recreational drug use [15], also implicated in many comorbidities.

Several controlled studies have revealed an increased prevalence of MM and comorbidities in PLWH. In 2011, an Italian study assessed the prevalence of noncommunicable diseases and MM in a cohort of PLWH compared to age-, sex-, and race-matched controls [16]; the prevalence of MM in PLWH anticipated those observed in the controls by 10 years. A Dutch study [17] also found a higher prevalence of high blood pressure, myocardial infarction, peripheral artery disease, and impaired renal function in PLWH. Another Italian study found an association between the prevalence of comorbidities and the duration of HIV disease [18]. To assess the impact of MM, a specific index has been developed in PLWH: the Veterans Aging Cohort Study (VACS) index (https:// medicine.yale.edu/intmed/vacs/welcome/vacsindexinfo.aspx). This index predicted hospitalizations and all-cause mortality [19, 20] and has been associated with frailty [21].

Additional studies on MM prevalence in elderly PLWH are needed. Elderly PLWH are probably very heterogeneous in terms of duration of HIV disease, with people acquiring the virus at an advanced age and therefore only recently exposed to HIV and cART, compared with people contracting the infection at earlier ages, with longer expositions. In this study, we sought to evaluate the association between MM and calendar periods of HIV diagnosis in an HIV-infected population aged $\geq 70$ years, and tested the hypothesis that PLWH with a longer history of known HIV diagnosis are associated with increased risk of MM after adjusting for confounders.

\section{METHODS}

\section{Study Population}

This cross-sectional study recruited persons from the Dat'AIDS French national multicentric cohort. Dat'AIDS is a prospective cohort of 71141 subjects that covers inpatients and outpatients with HIV infection treated in 23 French public hospitals, including French overseas territories. It is based on a computerized real-time medical record that is used by clinicians who collect, during consultation, demographic, behavioral, epidemiological, clinical, and biological information in a database using anonymous, coded identification numbers. All subjects included in the cohort had received oral information and given written consent. The Dat'AIDS cohort is registered on ClinicalTrials.gov under the identifier NCT02898987.

To be included in this analysis, subjects were at least 70 years old at the extraction date (14 of December 2018), with a laboratoryconfirmed HIV infection, and had consulted in their HIV clinic at least once between 1 January 2017 and 29 September 2018.

\section{Data Collected}

We retrieved the following characteristics: age, gender, body mass index (BMI), HIV exposure group, AIDS history, last CD4 cell count, HIV RNA load, CD4 nadir, CD4/CD8 ratio, hepatitis B virus (HBV)/hepatitis $\mathrm{C}$ virus (HCV) coinfection status (defined as the presence of hepatitis B surface antigen or HCV-positive serology, respectively), hemoglobin, creatinine, aminotransferase, platelet count, HIV disease duration, and duration of cART.

We divided subjects according to 3 calendar periods of HIV diagnosis. The first group consisted of PLWH diagnosed between 1983 and 1996, the second between 1997 and 2007, and the third between 2007 and 2018. These periods correspond to therapeutic breakthroughs in management of PLWH: 1997 with the first efficient cART [22], and 2007-2018 with second-generation boosted protease inhibitors and first-generation integrase inhibitors [23, 24].

We used International Classification of Diseases, Tenth Revision codes to retrieve comorbidities: cardiovascular disease, which included atherosclerosis and ischemic heart disease; cerebrovascular disease; diabetes mellitus, osteoporosis, non-AIDS cancer, high blood pressure (HBP). Additional information was obtained from the charts. Diabetes mellitus was also defined by the prescription of antidiabetic drugs at the 2 last visits, except for insulin monotherapy, which is commonly used in acute stress situations or type 1 diabetes. Osteoporosis also included subjects with a prescription of bisphosphonates or subjects with a previous dual X-ray absorptiometry (DEXA) T-score $<-2.5$ standard deviations. HBP also encompassed use of antihypertensive drugs at the last 2 medical visits, excluding subjects on $\beta$-blockers or furosemide monotherapy, commonly prescribed for other morbidities. We also added as comorbidities obesity (BMI $\left.\geq 30 \mathrm{~kg} / \mathrm{m}^{2}\right)$ and undernutrition $\left(\mathrm{BMI}<21 \mathrm{~kg} / \mathrm{m}^{2}\right)$, hypercholesterolemia if reported low-density lipoprotein cholesterol levels were $>1.6 \mathrm{~g} / \mathrm{L}$ and/or if subjects were on hypolipidemic drug (excluding fenofibrates) at the 2 last visits, and impaired renal function if estimated glomerular filtration rate (eGFR) was $<60 \mathrm{~mL} /$ minute in 2 consecutive measures using the Chronic Kidney Disease Epidemiology Collaboration (CKD-EPI) estimating equation. According to

2 CID 2020:XX (XXXXXX) - Demontès et al 
our health authorities, undernutrition must be suspected if an elderly person has a $\mathrm{BMI}<21 \mathrm{~kg} / \mathrm{m}^{2}$.

The VACS index was calculated for each patient, summing points according to the variables of the index: age, CD4 cell count, HIV RNA, HCV coinfection, hemoglobin, Fibrosis-4 Index for Liver Fibrosis (FIB-4), creatinine clearance (eGFR). The hepatic fibrosis score FIB-4 is calculated using a formula that incorporates age, aminotransferase level, and platelet count.

\section{Statistical Analysis}

The primary outcome was the prevalence of MM, defined as the coexistence of 3 or more comorbidities, excluding HIV. The choice of 3 comorbidities as an outcome for MM is published [4], and was justified in our study by the high prevalence of morbidities. Secondary analysis used the number of morbidities for each subject as a continuous variable and the VACS index as an outcome.

We compared the distributions of prespecified variables across the 3 calendar periods using $\chi^{2}$ tests for qualitative variables and Kruskal-Wallis tests for continuous variables, respectively. These variables were age, gender, smoking status, HBV/ HCV coinfection, HIV-acquisition exposed group, HIV RNA load ( $\geq 50$ vs $<50$ copies/mL), nadir CD4 count ( $<200$ vs $\geq 200$ cells $/ \mu \mathrm{L}$ ), last CD 4 count ( $<500$ vs $\geq 500$ cells $/ \mu \mathrm{L}$ ), last CD $4 / C D 8$ ratio ( $<0.8$ vs $\geq 0.8$ ), CDC stage $\mathrm{C}$, and calendar period of $\mathrm{HIV}$ diagnosis. We then tested these variables and their association with MM in univariate and multivariable analysis using logistic regression models. When using the number of morbidities as a continuous outcome, we included the prespecified variables in a linear regression model. We also evaluated the association of these variables with the VACS index.

In a sensitivity analysis, we excluded subjects with a nadir CD4 level $<200$ cells/ $\mu \mathrm{L}$ to address some of the classification bias. We aimed to exclude subjects with a long history of HIV infection and misclassified as recent HIV diagnosis (late presenters). In another sensitivity analysis, we tested age at HIV diagnosis instead of calendar period for its association with MM.

Statistical analysis was performed using Stata 15 software (StataCorp 2017, College Station, Texas).

\section{RESULTS}

\section{Demographics and Clinical Characteristics}

Between 1 January 2017 and 29 September 2018, 2627 subjects fulfilled the inclusion criteria: 151 were excluded because of missing weight measures (Figure 1). Baseline characteristics between included and nonincluded subjects were similar concerning calendar period of HIV diagnosis, gender, group of exposure, smoking status, and HBV/HCV coinfection.

We analyzed 2476 subjects. Median age was 73 years, $75 \%$ were male, $51 \%$ were heterosexual, $36 \%$ were men who had sex with men (MSM), and $8 \%$ were born in Sub-Saharan Africa. Less than $1 \%$ acquired HIV through intravenous drug use. More than $94 \%$ were on cART, and $36 \%$ were ever smokers. Median duration of HIV infection and cART were 20.2 and 17.9 years, respectively. Median CD4 count was 578 cells/ $\mu \mathrm{L} ; 94 \%$ had undetectable viral load ( $<50$ copies $/ \mathrm{mL}$ ), and median nadir CD4 count was 175 cells $/ \mu \mathrm{L}$.

Patients' characteristics are presented in Table 1. Subjects diagnosed between 1983 and 1996 were significantly older, though the actual difference in years was minimal. Subjects in this group were more frequently MSM, with a higher proportion of subjects with CD4 counts nadir $<200$ cells $/ \mu \mathrm{L}$, a higher proportion of AIDS-defining disease, a lower CD4/CD8 median ratio, and higher rates of HCV or HBV infections. Last T-lymphocyte CD4 counts were lower in the recent period after 2007 (Table 1).

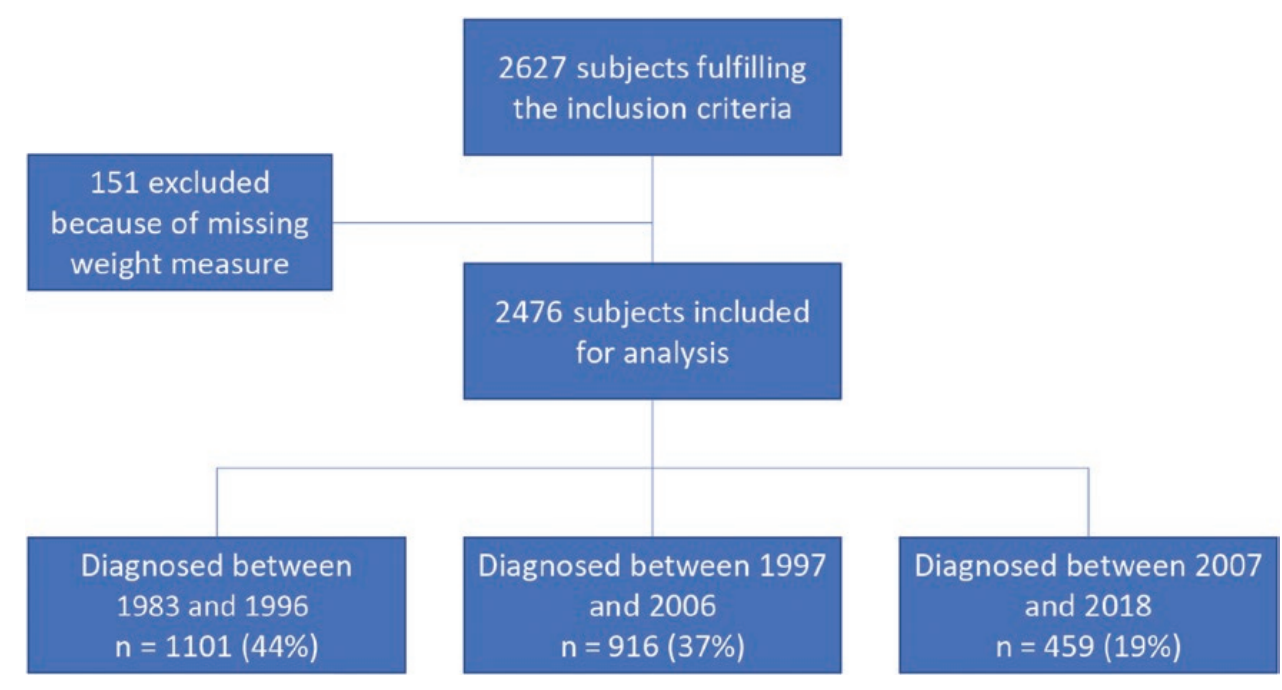

Figure 1. Flowchart with distribution of study population by calendar periods of human immunodeficiency virus diagnosis. 


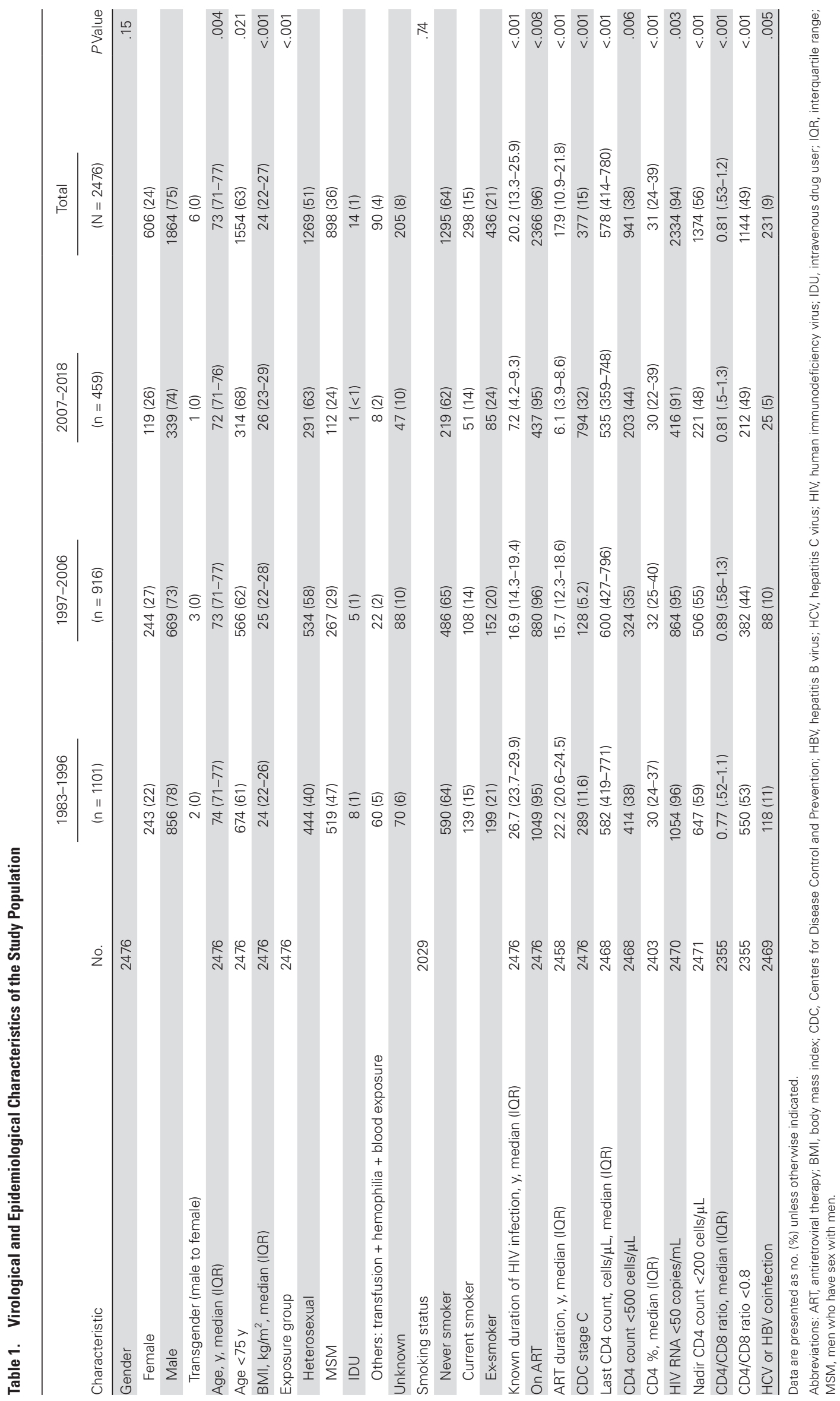




\begin{tabular}{|c|c|c|c|c|c|c|}
\hline Outcome & No. & $1983-1996(n=1101)$ & $1997-2006(n=916)$ & $2007-2018(n=459)$ & Total $(\mathrm{N}=2476)$ & PValue \\
\hline Multimorbidity ( $\geq 3$ comorbidities), No. (\%) & 2476 & $809(73)$ & $635(69)$ & $311(68)$ & $1755(71)$ & .033 \\
\hline No. of comorbidities, median (IQR) & 2476 & $3(2-4)$ & $3(2-4)$ & $3(2-4)$ & $3(2-4)$ & .028 \\
\hline No. of comorbidities, mean (SD) & 2476 & $3.34(1.43)$ & $3.24(1.44)$ & $3.12(1.46)$ & $3.26(1.44)$ & .028 \\
\hline VACS index, median (IQR) & 1656 & 39 (33-49) & $43(33-53)$ & $43(33-49)$ & $43(33-52)$ & .294 \\
\hline
\end{tabular}

Multimorbidity was defined as the presence of $\geq 3$ morbidities.

Abbreviations: IQR, interquartile range; SD, standard deviation; VACS, Veterans Aging Cohort Study.

\section{Outcomes}

MM prevalence, median and mean number of morbidities, and VACS index are shown in Table 2. Prevalence of MM, median, and mean number of morbidities was significantly lower in the more recent calendar period of HIV diagnosis. VACS index scores did not differ according to the calendar period.

Details of morbidities are shown in Figure 2. Prevalence of diabetes mellitus, cerebrovascular disease, non-AIDS cancer, and impaired renal function was similar in each of the 3 periods of HIV diagnosis. HBP, ischemic heart disease, hypercholesterolemia, osteoporosis, and undernutrition had lower prevalence in PLWH diagnosed more recently, whereas prevalence of obesity was higher.

Of the 2476 subjects, 1921 subjects were included for multivariable analysis as 555 had missing data. Subjects excluded were more often diagnosed in the last calendar period of HIV diagnosis, had shorter duration of cART, and had increased median nadir CD4 count, but were similar for age, sex, smoking status, last CD4 cell count, CD4/CD8 ratio, and HIV RNA load.

In univariate analysis, factors associated with MM were age, calendar period of HIV diagnosis, CD4/CD8 ratio, and nadir CD4 count $<200$ cells/ $\mu \mathrm{L}$ (Table 3 ). We decided to include all variables in the multivariable analysis, as we had sufficient power, and to force in the model HIV viral load $<50$ (copies/mL) and HBV/HCV coinfection despite a $P>.20$ in univariate analysis for these two variables. After adjustment, the association between MM and calendar period of HIV diagnosis was not significant. MM was associated with older age, $\mathrm{CD} 4 / \mathrm{CD} 8$ ratio $<0.8$, and nadir CD4 count $<200$ cells $/ \mu \mathrm{L}$.

In the secondary analysis, comorbidities as a continuous outcome were associated with calendar period of HIV diagnosis in univariate analysis $(P=.028)$, but not in multivariable analysis (Table 4). In this analysis, older age, CD4/CD8 ratio $<0.8$, and nadir CD 4 count $<200$ cells/ $\mu \mathrm{L}$ were also associated with $\mathrm{MM}$, as was $\mathrm{HBV} / \mathrm{HCV}$ coinfection. The VACS index was calculated for 1656 subjects. Mean value of VACS score was 43 points in our study, with no difference between the 3 groups. VACS score was not associated with calendar period of HIV diagnosis $(P=.294$; data not shown).
Excluding subjects with a nadir CD 4 count $<200$ cells $/ \mu \mathrm{L}$ in the secondary analysis did not modify results, as calendar period of HIV diagnosis was not associated with MM $(P=.169$; data not shown). Age at HIV diagnosis as a continuous variable was not associated with MM. In this last analysis, MM was also associated with older age, CD4/CD8 ratio $<0.8$, and nadir CD4 count $<200$ cells $/ \mu \mathrm{L}$ (Supplementary Table 1 ).

\section{DISCUSSION}

We evaluated whether MM was associated with periods of HIV diagnosis, after adjusting for relevant covariates, in a geriatric population of PLWH. Our results showed that the prevalence of MM was high and associated with age, low ratio CD4/CD8, and a nadir CD 4 count $<200$ cells/ $\mu \mathrm{L}$ but not with the calendar period of HIV diagnosis.

Our study is one of the few focusing on a geriatric population within a large national cohort of PLWH. In our study, prevalence of morbidities and MM seemed higher than those observed in previous publications of PLWH [16-18, 25, 26]. Discrepancies between studies can be explained by the advanced age of our subjects, difference in population characteristics and hazard risk exposures, but also by the extensive choice of morbidities assessed, as well as differences in morbidity definitions. As in our study, all previous studies highlighted high rates of MM in the aging PLWH.

We observed in more recent periods of HIV diagnosis a significant decrease in the prevalence of HBP, hypercholesterolemia, osteoporosis, ischemic heart disease, and undernutrition, and a significant increase in obesity. Rates of diabetes mellitus and renal failure were stable across periods. Despite these varying rates of morbidities with periods of HIV diagnosis, low nadir CD4 levels and CD4/ CD8 ratio better correlated with MM. These results were further confirmed by the lack of association between age at HIV diagnosis (a proxy of HIV known duration) and MM in secondary analysis, as well as the persistence of an association with nadir CD4 levels and CD4/CD8 ratio in all secondary and sensitivity analysis.

Other factors associated with MM in our study have been previously published. Age is a marker of MM, in PLWH [16] and in the general population [27]. The CD4/CD8 ratio is a 


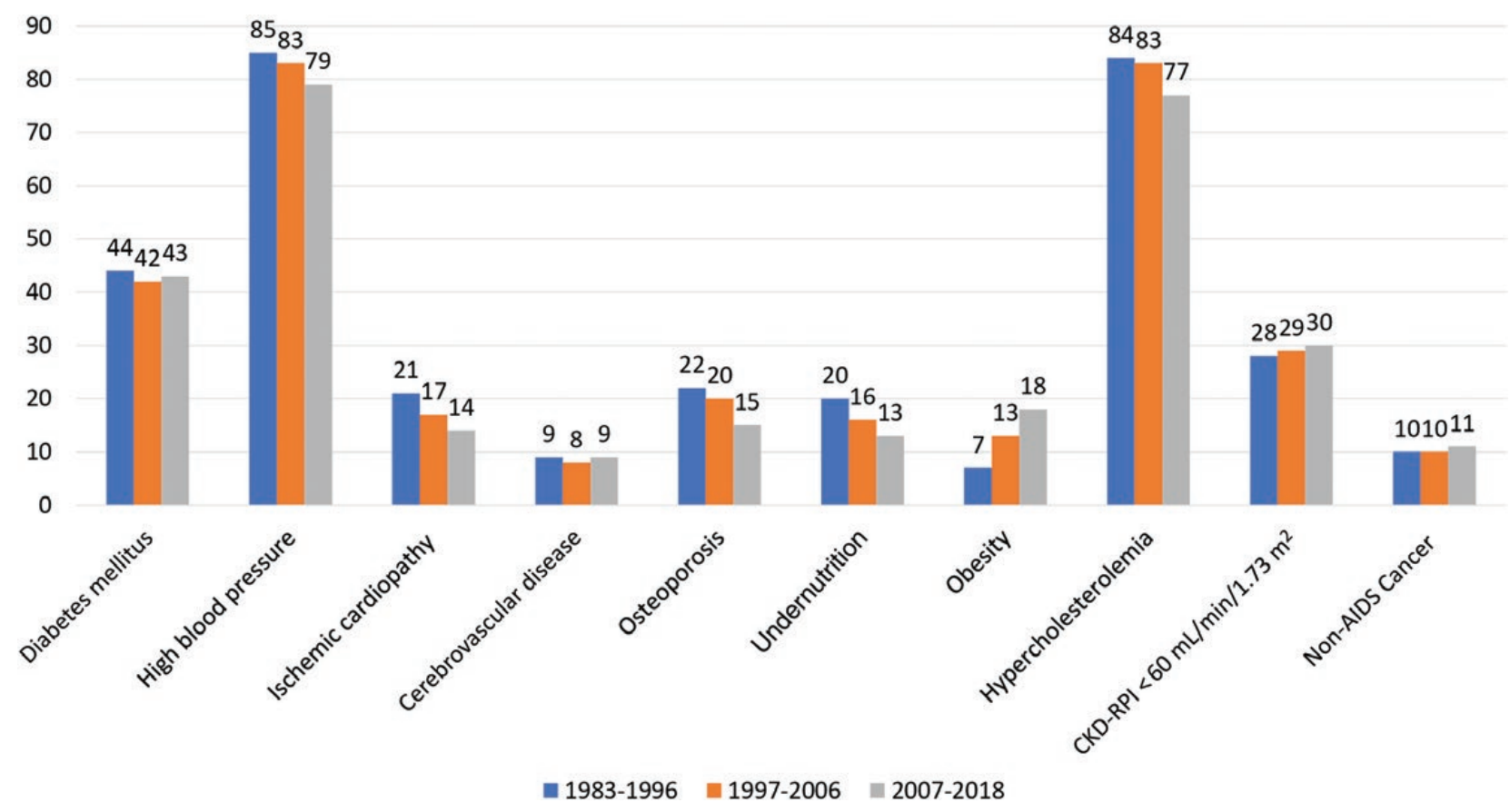

Figure 2. Prevalence of each comorbidity included in the outcomes according to the calendar period of human immunodeficiency virus diagnosis. Abbreviation: CKD-EPI, chronic kidney disease epidemiology collaboration.

marker of immune restoration reflecting residual activation and inflammation, and has been associated with comorbidities in PLWH, including lung cancer [28], and non-AIDS-defining diseases $[29,30]$. There is also evidence that low nadir CD4 cell values are associated with a higher prevalence of MM [16] in $\mathrm{PLWH}$. The absence of correlation with viral load or HCV/HBV in our study may be a result of low numbers, as $>90 \%$ of the studied subjects were either virologically controlled or HCV/ HBV negative.

There was a nonsignificant trend between smoking status and MM. Some of the morbidities defining our MM endpoint are not strongly correlated to smoking, such as obesity, undernutrition, diabetes, and hypercholesterolemia. Also, proportions of active smokers were low in our study, and possible survival bias, with

\section{Table 3. Factors Associated With Multimorbidity ( $\geq 3$ Comorbidities)}

\begin{tabular}{|c|c|c|c|c|}
\hline \multirow[b]{2}{*}{ Factor } & \multicolumn{2}{|c|}{ Univariate Analysis } & \multicolumn{2}{|c|}{ Multivariable Analysis } \\
\hline & OR $(95 \% \mathrm{Cl})$ & $P$ Value & Adjusted OR (95\% Cl) & $P$ Value \\
\hline Age (per 5 years) & $1.12(1.02-1.23)$ & .021 & $1.14(1.02-1.28)$ & .026 \\
\hline Female & $1.15(1.02-1.23)$ & .185 & $1.25(.94-1.66)$ & .118 \\
\hline Smoking status & & .260 & & .075 \\
\hline Nonsmoker & 1 & & 1 & \\
\hline Ever smoker & $1.12(.92-1.38)$ & & $1.22(.98-1.52)$ & \\
\hline Exposure group & & .062 & & .083 \\
\hline Heterosexual & 1 & & 1 & \\
\hline MSM & $0.83(.69-1.00)$ & & $0.86(.67-1.10)$ & \\
\hline Others & $1.10(.83-1.46)$ & & $1.30(.91-1.85)$ & \\
\hline Calendar period of diagnosis & & .031 & & .169 \\
\hline 1983-1996 & 1 & & 1 & \\
\hline 1997-2006 & $0.81(.67-.99)$ & & $0.82(.65-1.03)$ & \\
\hline $2007-2018$ & $0.76(.60-.96)$ & & $0.81(.60-1.09)$ & \\
\hline HBV or HCV coinfection & $1.20(.88-1.63)$ & .255 & $1.14(.80-1.63)$ & .476 \\
\hline Last CD4 count $<500$ cells $/ \mu \mathrm{L}$ & $1.13(.94-1.35)$ & .185 & $0.98(.77-1.24)$ & .862 \\
\hline CD4/CD8 ratio $<0.8$ & $1.41(1.18-1.69)$ & $<.001$ & $1.40(1.12-1.76)$ & .003 \\
\hline Nadir CD4 count $<200$ cells $/ \mu \mathrm{L}$ & $1.59(1.33-1.89)$ & $<.001$ & $1.46(1.17-1.82)$ & .001 \\
\hline HIV RNA load <50 (copies/mL) & $1.02(.70-1.49)$ & .934 & $1.11(.68-1.79)$ & .683 \\
\hline
\end{tabular}

Abbreviations: $\mathrm{Cl}$, confidence interval; $\mathrm{HBV}$, hepatitis $\mathrm{B}$ virus; $\mathrm{HCV}$, hepatitis $\mathrm{C}$ virus; $\mathrm{HIV}$, human immunodeficiency virus; MSM, men who have sex with men; OR, odds ratio. 
Table 4. Factors Associated With Number of Comorbidities as a Continuous Variable in Multivariate Analysis

\begin{tabular}{|c|c|c|}
\hline Factor & Adjusted $\beta(95 \% \mathrm{Cl})$ & $P$ Value \\
\hline Age (per 5 years) & $.16(.09-.23)$ & $<.001$ \\
\hline Female & $.13(-.04$ to .30$)$ & .138 \\
\hline \multicolumn{3}{|l|}{ Smoking status } \\
\hline Nonsmoker & 1.00 & .007 \\
\hline Ever smoker & $.19(.05-.32)$ & \\
\hline \multicolumn{3}{|l|}{ Group of exposure } \\
\hline Heterosexual & 1.00 & .070 \\
\hline MSM & $-.16(-.31$ to .00$)$ & \\
\hline Others & .05 (-.15 to .26$)$ & \\
\hline \multicolumn{3}{|l|}{ Calendar period of diagnosis } \\
\hline 1983-1996 & 1.00 & .363 \\
\hline 1997-2006 & $-.08(-.22$ to .06$)$ & \\
\hline 2007-2017 & $-.11(-.29$ to .07$)$ & \\
\hline HBV or HCV coinfection & $.23(.02-.45)$ & .032 \\
\hline Last CD4 count $<500$ cells $/ \mu \mathrm{L}$ & $.10(-.04$ to .25$)$ & .160 \\
\hline CD4/CD8 ratio $<0.8$ & $.17(.03-.31)$ & .014 \\
\hline Nadir CD4 count $<200$ cells $/ \mu \mathrm{L}$ & $.29(.15-.43)$ & $<.001$ \\
\hline HIV RNA <50 copies/mL & $.26(-.04$ to .55$)$ & .086 \\
\hline
\end{tabular}

Abbreviations: $\mathrm{Cl}$, confidence interval; $\mathrm{HBV}$, hepatitis $\mathrm{B}$ virus; $\mathrm{HCV}$, hepatitis $\mathrm{C}$ virus; $\mathrm{HIV}$, human immunodeficiency virus; MSM, men who have sex with men.

increased mortality of active tobacco users, might explain our findings [31].

Most studies on HIV and comorbidities have confined comparisons between HIV-negative controls and PLWH in subjects with lower median ages $[16,17,25,32]$. In these studies, HIV populations were at higher risk of morbidities and MM compared to controls. In our study, subjects diagnosed with HIV between 1983 and 1996 could have been more prone to die prior to our analysis, another form of survival bias [33]. The fact that the VACS index was similar between calendar periods of HIV diagnosis could also be an illustration of survival bias, as only the fittest subjects, particularly in subjects diagnosed with HIV in the early periods, might have survived. There are some illustrations of survival bias in HIV-infected cohorts. The Antiretroviral Therapy Cohort Collaboration [6] showed that all-cause mortality and non-AIDS-related deaths in the second and third years after initiation of CART were lower for subjects starting treatment in 2008-2010 compared with those who started in 2000-2003, independent of viral load and CD4 levels. In the Swiss cohort [5] and in a Kaiser Permanente California study [34], life expectancy was much lower in intravenous drug users or subjects with lower CD4 levels, conditions more prevalent during the early periods of the HIV epidemic.

A relevant limit of our study is that morbidities counted as events whether they occurred prior to or after HIV diagnosis. Thus, the prevalence of comorbidities according to the calendar period of HIV diagnosis could have been related to unmeasured confounders, but not HIV per se. A recent Danish study revealed that in comparison with the general population, PLWH were at increased risk of comorbidities 10 years prior to their HIV diagnosis, revealing that environmental, behavioral, and social factors were important [35].

In conclusion, despite caveats inherent to a cross-sectional design, our results have important clinical implications. First, they underscore the high rates of comorbidities and MM in elderly PLWH, as well as the comorbidities at stake. Second, our study does not support periods of HIV diagnosis or durations of known HIV infection as an independent, clinically important factor associated with MM. Our finding may be a result of survival bias, but does not undermine the potential impact of HIV on MM, as other important HIV-associated factors such as nadir CD4 level or CD4/CD8 ratio were associated with the outcome. As such, the duration of HIV diagnosis seems not to be a criterion for selecting a geriatric population at risk of MM.

\section{Supplementary Data}

Supplementary materials are available at Clinical Infectious Diseases online. Consisting of data provided by the authors to benefit the reader, the posted materials are not copyedited and are the sole responsibility of the authors, so questions or comments should be addressed to the corresponding author.

\section{Note}

Potential conflicts of interest. D. R. reports personal fees from Mylan, and grants from Gilead Sciences and ViiV (supports for conferences expenses). J. R. reports personal fees from Gilead, and personal fees from ViiV Healthcare, Merck Sharp and Dohme (MSD), Janssen, and Pfizer, outside the submitted work. A. C. reports nonfinancial support from ViiV Healthcare and Gilead, outside the submitted work. C. J. reports personal fees from ViiV, MSD, Janssen, Mylan, Convergence Editions, and Gilead, and nonfinancial support from MSD, Janssen, Gilead, and AbbVie, outside the submitted work. L. H. reports personal fees and nonfinancial support from Gilead, ViiV Healthcare, and Merck, outside the submitted work. All other authors report no potential conflicts of interest. All authors have submitted the ICMJE Form for Disclosure of Potential Conflicts of Interest. Conflicts that the editors consider relevant to the content of the manuscript have been disclosed.

\section{References}

1. van den Akker M, Buntinx F, Metsemakers JF, Roos S, Knottnerus JA. Multimorbidity in general practice: prevalence, incidence, and determinants of co-occurring chronic and recurrent diseases. J Clin Epidemiol 1998; 51:367-75.

2. Verbrugge LM, Lepkowski JM, Imanaka Y. Comorbidity and its impact on disability. Milbank Q 1989; 67:450-84.

3. Marengoni A, von Strauss E, Rizzuto D, Winblad B, Fratiglioni L. The impact of chronic multimorbidity and disability on functional decline and survival in elderly persons. A community-based, longitudinal study. J Intern Med 2009; 265:288-95.

4. Marengoni A, Angleman S, Melis R, et al. Aging with multimorbidity: a systematic review of the literature. Ageing Res Rev 2011; 10:430-9.

5. Gueler A, Moser A, Calmy A, et al; Swiss HIV Cohort Study, Swiss National Cohort. Life expectancy in HIV-positive persons in Switzerland: matched comparison with general population. AIDS 2017; 31:427-36.

6. Antiretroviral Therapy Cohort Cohort. Survival of HIV-positive patients starting antiretroviral therapy between 1996 and 2013: a collaborative analysis of cohort studies. Lancet HIV 2017; 4:e349-56.

7. Smit M, Brinkman K, Geerlings S, et al; ATHENA Observational Cohort. Future challenges for clinical care of an ageing population infected with HIV: a modelling study. Lancet Infect Dis 2015; 15:810-8.

8. Morlat P, Roussillon C, Henard S, et al; ANRS EN20 Mortalité 2010 Study Group. Causes of death among HIV-infected patients in France in 2010 (national survey): trends since 2000. AIDS 2014; 28:1181-91. 
9. Desai S, Landay A. Early immune senescence in HIV disease. Curr HIV/AIDS Rep 2010; 7:4-10.

10. Carr A, Hudson J, Chuah J, et al; PIILR Study Group. HIV protease inhibitor substitution in patients with lipodystrophy: a randomized, controlled, open-label, multicentre study. AIDS 2001; 15:1811-22.

11. Friis-Møller N, Reiss P, Sabin CA, et al; DAD Study Group. Class of antiretroviral drugs and the risk of myocardial infarction. N Engl J Med 2007; 356:1723-35.

12. Mary-Krause M, Cotte L, Simon A, Partisani M, Costagliola D; Clinical Epidemiology Group from the French Hospital Database. Increased risk of myocardial infarction with duration of protease inhibitor therapy in HIV-infected men. AIDS 2003; 17:2479-86.

13. Tron L, Lert F, Spire B, Dray-Spira R; Agence Nationale de Recherche sur le Sida et les Hépatites Virales (ANRS)-Vespa2 Study Group. Levels and determinants of breast and cervical cancer screening uptake in HIV-infected women compared with the general population in France. HIV Med 2017; 18:181-95.

14. Mimiaga MJ, Reisner SL, Grasso C, et al. Substance use among HIV-infected patients engaged in primary care in the United States: findings from the Centers for AIDS Research Network of Integrated Clinical Systems cohort. Am J Public Health 2013; 103:1457-67.

15. Jacquet JM, Peyriere H, Makinson A, et al; MesConsos Study Group. Psychoactive substances, alcohol and tobacco consumption in HIV-infected outpatients. AIDS 2018; 32:1165-71.

16. Guaraldi G, Orlando G, Zona S, et al. Premature age-related comorbidities among $\mathrm{HIV}$-infected persons compared with the general population. Clin Infect Dis 2011; 53:1120-6.

17. Schouten J, Wit FW, Stolte IG, et al; AGEhIV Cohort Study Group. Cross-sectional comparison of the prevalence of age-associated comorbidities and their risk factors between HIV-infected and uninfected individuals: the AGEhIV cohort study. Clin Infect Dis 2014; 59:1787-97.

18. Guaraldi G, Zona S, Brothers TD, et al. Aging with HIV vs. HIV seroconversion at older age: a diverse population with distinct comorbidity profiles. PLoS One 2015; 10:e0118531.

19. Bebu I, Tate J, Rimland D, et al; Infectious Disease Clinical Research Program HIV Working Group. The VACS index predicts mortality in a young, healthy HIV population starting highly active antiretroviral therapy. J Acquir Immune Defic Syndr 2014; 65:226-30

20. Justice AC, Modur SP, Tate JP, et al; NA-ACCORD and VACS Project Teams. Predictive accuracy of the Veterans Aging Cohort Study index for mortality with HIV infection: a North American cross cohort analysis. J Acquir Immune Defic Syndr 2013; 62:149-63.

21. Womack JA, Goulet JL, Gibert C, et al; Veterans Aging Cohort Study Project Team. Physiologic frailty and fragility fracture in HIV-infected male veterans. Clin Infect Dis 2013; 56:1498-504.

22. Palella FJ Jr, Delaney KM, Moorman AC, et al. Declining morbidity and mortality among patients with advanced human immunodeficiency virus infection. HIV Outpatient Study Investigators. N Engl J Med 1998; 338:853-60.

23. Lennox JL, DeJesus E, Lazzarin A, et al; STARTMRK Investigators. Safety and efficacy of raltegravir-based versus efavirenz-based combination therapy in treatment-naive patients with HIV-1 infection: a multicentre, double-blind randomised controlled trial. Lancet 2009; 374:796-806.

24. Ortiz R, Dejesus E, Khanlou H, et al. Efficacy and safety of once-daily darunavir/ ritonavir versus lopinavir/ritonavir in treatment-naive HIV-1-infected patients at week 48. AIDS 2008; 22:1389-97.

25. Althoff KN, McGinnis KA, Wyatt CM, et al; Veterans Aging Cohort Study (VACS). Comparison of risk and age at diagnosis of myocardial infarction, endstage renal disease, and non-AIDS-defining cancer in HIV-infected versus uninfected adults. Clin Infect Dis 2015; 60:627-38.

26. Allavena C, Hanf M, Rey D, et al; Dat'AIDS Study Group. Antiretroviral exposure and comorbidities in an aging HIV-infected population: the challenge of geriatric patients. PLoS One 2018; 13:e0203895.

27. Feely A, Lix LM, Reimer K. Estimating multimorbidity prevalence with the Canadian Chronic Disease Surveillance System. Health Promot Chronic Dis Prev Can 2017; 37:215-22.

28. Sigel K, Wisnivesky J, Crothers K, et al. Immunological and infectious risk factors for lung cancer in US veterans with HIV: a longitudinal cohort study. Lancet HIV 2017; 4:e67-73

29. Serrano-Villar S, Moreno S, Fuentes-Ferrer M, et al. The CD4:CD8 ratio is associated with markers of age-associated disease in virally suppressed HIV-infected patients with immunological recovery. HIV Med 2014; 15:40-9.

30. Castilho JL, Shepherd BE, Koethe J, et al. CD4+/CD8+ ratio, age, and risk of serious noncommunicable diseases in HIV-infected adults on antiretroviral therapy. AIDS 2016; 30:899-908.

31. Burns DM. Cigarette smoking among the elderly: disease consequences and the benefits of cessation. Am J Health Promot 2000; 14:357-61.
32. Rasmussen LD, Engsig FN, Christensen H, et al. Risk of cerebrovascular events in persons with and without HIV: a Danish nationwide population-based cohort study. AIDS 2011; 25:1637-46.

33. Kelly SG, Wu K, Tassiopoulos K, Erlandson KM, Koletar SL, Palella FJ. Frailty is an independent risk factor for mortality, cardiovascular disease, bone disease, and diabetes among aging adults with human immunodeficiency virus. Clin Infect Dis 2019; 69:1370-6.

34. Marcus JL, Chao CR, Leyden WA, et al. Narrowing the gap in life expectancy between HIV-infected and HIV-uninfected individuals with access to care. J Acquir Immune Defic Syndr 2016; 73:39-46.

35. Ronit A, Gerstoft J, Nielsen L, et al. Non-AIDS comorbid conditions in persons living with human immunodeficiency virus (HIV) compared with uninfected individuals 10 years before HIV diagnosis. Clin Infect Dis 2018; $67: 1291-3$

\section{APPENDIX}

Dat'AIDS Study Group. C. Drobacheff-Thiébaut, A. Foltzer, K. Bouiller, L. Hustache- Mathieu, C. Chirouze, Q. Lepiller, F. Bozon, O Babre, A. S. Brunel, P. Muret (Besançon); H. Laurichesse, O. Lesens, M. Vidal, N. Mrozek, C. Aumeran, O. Baud, V. Corbin, P. Letertre-Gibert, S. Casanova, J. Prouteau, C. Jacomet (Clermont Ferrand); I. Lamaury, I. Fabre, E. Curlier, R. Ouissa, C. Herrmann-Storck, B. Tressieres, T. Bonijoly, M. C. Receveur, F. Boulard, C. Daniel, C. Clavel (Guadeloupe); D. Merrien, P. Perré, T. Guimard, O. Bollangier, S. Leautez, M. Morrier, L. Laine (La Roche sur Yon); F. Ader, A. Becker, F. Biron, A. Boibieux, L. Cotte, T. Ferry, P. Miailhes, T. Perpoint, S. Roux, C. Triffault-Fillit, S. Degroodt, C. Brochier, F. Valour, C. Chidiac (Lyon); A. Ménard, A. Y. Belkhir, P. Colson, C. Dhiver, A. Madrid, M. Martin-Degiovani, L. Meddeb, M. Mokhtari, A. Motte, A. Raoux, I. Ravaux, C. Tamalet, C. Toméi, H. Tissot Dupont (Marseille IHU Méditerranée); S. Brégigeon, O. ZaegelFaucher, V. Obry-Roguet, H. Laroche, M. Orticoni, M. J. Soavi, P. Geneau de Lamarlière, E. Ressiot, M. J. Ducassou, I. Jaquet, S. Galie, A. Galinier, P. Martinet, M. Landon, A. S. Ritleng, A. Ivanova, C. Debreux, C. Lions, I. Poizot-Martin (Marseille Ste Marguerite); S. Abel, O. Cabras, L. Cuzin, K. Guitteaud, M. Illiaquer, S. Pierre-François, L. Osei, J. Pasquier, K. Rome, E. Sidani, J. M. Turmel, C. Varache, A. Cabié (Martinique); N. Atoui, M. Bistoquet, E. Delaporte, V. Le Moing, A. Makinson, N. Meftah, C. Merle de Boever, B. Montes, A. Montoya Ferrer, E. Tuaillon, J. Reynes (Montpellier); M. André, L. Boyer, M. P. Bouillon, M. Delestan, C. Rabaud, T. May, B. Hoen (Nancy); C. Allavena, C. Bernaud, E. Billaud, C. Biron, B. Bonnet, S. Bouchez, D. Boutoille, C. Brunet-Cartier, C. Deschanvres, N. Hall, T. Jovelin, P. Morineau, V. Reliquet, S. Sécher, M. Cavellec, A. Soria, V. Ferré, E. André-Garnier, A. Rodallec, M. Lefebvre, O. Grossi, O. Aubry, F. Raffi (Nantes); P. Pugliese, S. Breaud, C. Ceppi, D. Chirio, E. Cua, P. Dellamonica, E. Demonchy, A. De Monte, J. Durant, C. Etienne, S. Ferrando, R. Garraffo, C. Michelangeli, V. Mondain, A. Naqvi, N. Oran, I. Perbost, S. Pillet, C. Pradier, B. Prouvost-Keller, K. Risso, V. Rio, P. M. Roger, E. Rosenthal, S. Sausse, I. Touitou, S. Wehrlen-Pugliese, G. Zouzou (Nice); L. Hocqueloux, T. Prazuck, C. Gubavu, A. Sève, A. Maka, C. Boulard, G. Thomas (Orleans); A. Cheret, C. Goujard, 
Y. Quertainmont, E. Teicher, N. Lerolle, O. Deradji, A. BarrailTran (Paris Hop. Bicètre); R. Landman, V. Joly, J. Ghosn, C. Rioux, S. Lariven, A. Gervais, F. X. Lescure, S. Matheron, F. Louni, Z. Julia, C. Mackoumbou-Nkouka, S. Le Gac, C. Charpentier, D. Descamps, G. Peytavin, Y. Yazdanpanah (Paris Hop. Bichat); K. Amazzough, V. Avettand-Fenoël, G. Benabdelmoumen, P. Bossi, G. Cessot, C. Charlier, P. H. Consigny, F. Danion, A. Dureault, C. Duvivier, J. Goesch, R. Guery, B. Henry, K. Jidar, F. Lanternier, P. Loubet, O. Lortholary, C. Louisin, J. Lourenco, P. Parize, B. Pilmis, F. Touam (Paris Hop. Necker Pasteur); M. A. Valantin, R. Tubiana, R. Agher, S. Seang, L. Schneider, R. Palich, C. Blanc, C. Katlama (Paris Hop. Pitié Salpétrière); J. L. Berger, Y. N'Guyen, D. Lambert, I. Kmiec, M. Hentzien, A. Brunet,
V. Brodard, F. Bani-Sadr (Reims); P. Tattevin, M. Revest, F. Souala, M. Baldeyrou, S. Patrat-Delon, J. M. Chapplain, F. Benezit, M. Dupont, M. Poinot, A. Maillard, C. Pronier, F. Lemaitre, C. Guennoun, M. Poisson-Vanier, T. Jovelin, J. P. Sinteff, C. Arvieux (Rennes); E. Botelho-Nevers, A. Gagneux-Brunon, A. Frésard, V. Ronat, F. Lucht (St Etienne); P. Fischer, M. Partisani, C. Cheneau, M. Priester, M. L. Batard, C. Bernard-Henry, E. de Mautort, S. Fafi-Kremer, D. Rey (Strasbourg); M. Alvarez, N. Biezunski, A. Debard, C. Delpierre, P. Lansalot, L. Lelièvre, G. Martin-Blondel, M. Piffaut, L. Porte, K. Saune, P. Delobel (Toulouse); F. Ajana, E. Aïssi, I. Alcaraz, V. Baclet, L. Bocket, A. Boucher, P. Choisy, T. Huleux, B. Lafon-Desmurs, A. Meybeck, M. Pradier, O. Robineau, N. Viget, M. Valette (Tourcoing). 